\title{
LA CIRCUNCISIÓN EN EL ARTE REUGIOSO.
}

\author{
Daniel Santos Arrontes, M ónica Santos Arrontes y María Paz Valer López-Fando ${ }^{1}$
}

Servicio de Urología. Hospital Santa Bárbara. Puertollano. Ciudad Real. España y Práctica privada ${ }^{1}$

Resumen.- O BJETIVO S: El objetivo de este estudio es hacer un recorrido histórico de la circuncisión en la pintura desde el Renacimiento Italiano al Barroco Español.

MÉTO DO S: Se evaluaron las pinturas sobre el tema de la circuncisión entre ambos períodos, incluyéndose las obras más representativas.

RESULTADOS Y CON CLUSION ES: La circuncisión es un tema ampliamente tratado en la pintura religiosa en estos períodos.

Palabras clave: Circuncisión. Arte en medicina.

Pinturas.
Summary.- O BJEC TIVES: The objective of this study is to perform a historical journey through the topic of circumcision from the Italian Renaissance to the Spanish Baroque.

METHO DS: W e evaluated the paintings about circumcision betw een both periods, including their most representative works.

RESULTS AN D CON CLUSION S: C ircumcision is a frequent topic in the religious painting in both periods.

Keywords: Circumcision. Medicine in art Paintings.

\section{INTRODUCCIÓN}

La circuncisión es un rito iniciático, que se vincula a las culturas mesopotámicas y del levante mediterráneo, fuertemente influenciadas por las culturas sumeria, acadia y babilonia hacia el año 2000 a.C. Entre estos pueblos, destacaban los pueblos semíticos, descendientes de Sem, hijo de N oe, y cuyo origen hay que situarlo en la península arábiga. El rito de la circuncisión era practicado por un sacerdote médico y pretendía la Alianza del recién nacido con la comunidad de la que formaba parte, ya que Dios había recomendado la circuncisión a Abraham, y a todos sus descendientes como prueba de fe, y como purificación 
por el pecado original. Cristo nació dentro de una de estas comunidades semíticas, la judía, siendo circuncidado, según el Nuevo Testamento, a los 8 días de nacer, es decir, el 1 de enero según la tradición, fecha celebrada todavía hoy por los pueblos cristianos como A ño Nuevo.

A pesar de tener el cristianismo su origen en la religión judía, y que la Biblia lo recomienda expresamente para todos los varones (G énesis 17.11.14), la práctica de la circuncisión no perduró en la nueva religión, debido sobre todo a presiones de algunos de los primeros discípulos, en especial Pablo de Tarso, San Pablo, que excluyeron el rito de las reglas básicas del cristianismo hacia el $50 \mathrm{~d}$. C., desvinculándolo de esta forma de las prácticas judías, al considerar que si Cristo nació sin el pecado original, pudo no haber sido circuncidado, y que si lo fue, el motivo hay que buscarlo en la tradición del pueblo en el que nació. A unque no la más importante ni la única, la diferencia doctrinal del rito tanto en sus formas física como simbólica constituye una de las causas de separación a mbas religiones.

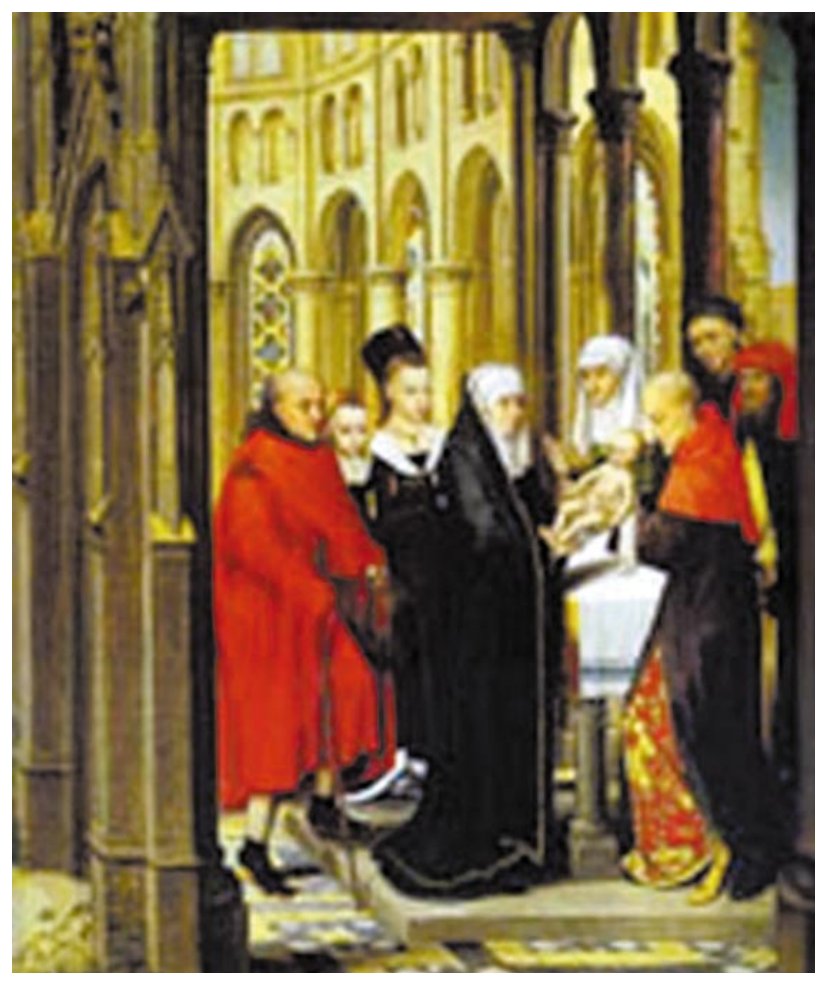

FIG URA 1: Circuncisión o Presentación en el Templo. Hans Memling, 1470. Lateral del Tríptico de la Adoración de los Reyes o Tríptico de la Epifanía. Gótico Flamenco. (M useo del Prado).
N o obstante, es un tema ampliamente tratado en la pintura religiosa. Algunos de los pintores más representativos de cada época lo utilizaron por su simbolismo como parte de ciclos de la vida de Cristo, y por eso mismo nunca estuvo exento de polémicas, al subrayar el origen judaico del cristianismo, y con ello la preeminencia histórica del judaísmo sobre el cristianismo. Como veremos, muchas veces la circuncisión queda enmascarada en el arte en una presentación en el templo, aunque hay que precisar que se trata de dos momentos distintos a los que corresponden ritos diferentes: según la Biblia, la presentación en el templo de Jesús tuvo lugar a los cuarenta días de nacer, siguiendo las normas de purificación tras el parto, diferenciándolo claramente de la circuncisión, y aunque ambos ritos, en realidad, tengan que ver con la idea de continuidad y de pertenencia a un pueblo parece que la presentación en el templo, es menos polémica que la circuncisión, y por ello más "aceptable", en el arte occidental.

Uno de los primeros ejemplos de circuncisión en el arte occidental, lo tenemos en el "Tríptico de la

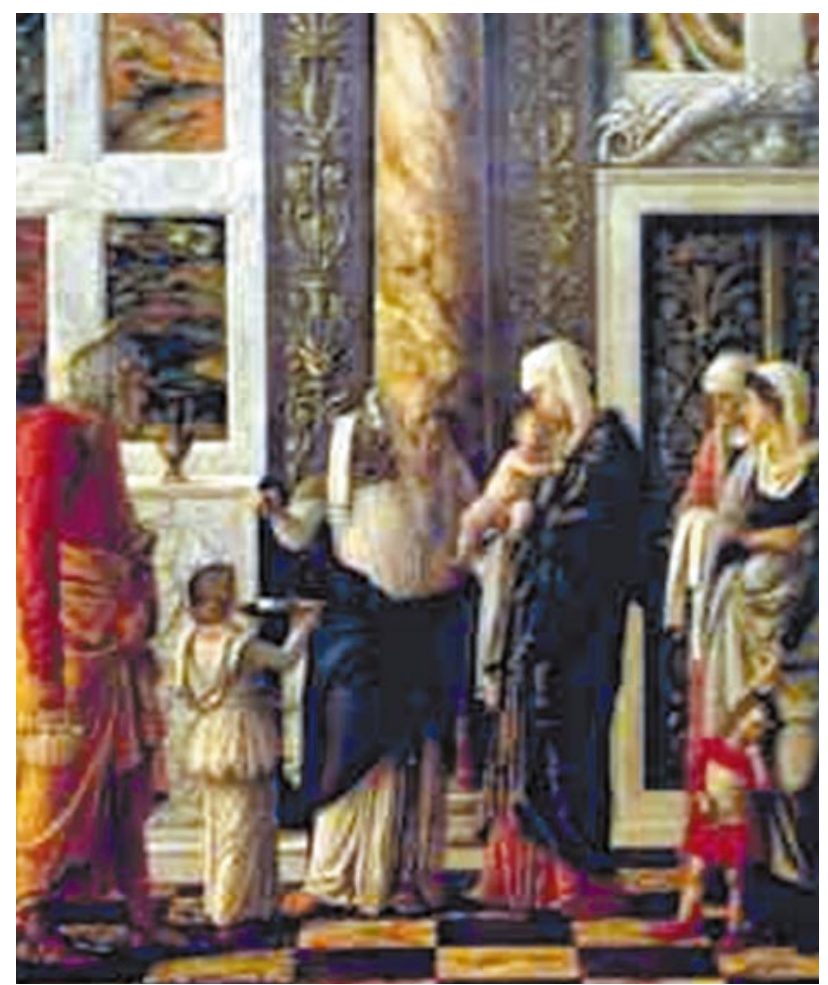

FIG URA 2: La Circuncisión. Andrea Mantenga, 1460. $(86 \times 42,4 \mathrm{~cm})$. Ó leo sobre tabla. Renacimiento Italiano. 
Epifanía" (hacia 1470), de Hans Memling (14331494) (Figura 1), formado en la tradición del gótico flamenco, y probable discípulo de Roger Van der W eyden, una de las figuras más importantes de entre los llamados primitivos flamencos, corriente en la que se inscriben pintores como Jan Van Eyck, Robert Campin, o el Bosco, y que desarrollaron su actividad de forma coetánea al primer renacimiento italiano, el $Q$ uattrocento, como reflejo de una nueva clase social, la burguesía, y como respuesta a las necesidades de ésta, como motor del desarrollo económico y comercial, y a la larga cultural de los Países Bajos del medievo.

"El Tríptico de la Epifanía", o "de la adoración de los magos", llamado así por su tabla central, se encuentra hoy en día en el Museo del Prado. "La Circuncisión", o "la presentación en el templo" , ocupa una de los laterales del tríptico, siguiendo el modelo creado por Van der Weyden, aunque sin su fuerza emotiva, ni la perfección técnica de los detalles tan propia de algunos de los más destacados primitivos flamencos, lo que ha hecho que en los últimos años su obra haya perdido cierto prestigio, y muchos críticos y expertos le acusen de falta de visión de conjunto, y de basarse sobre todo en la adición de elementos a la hora de componer la obra.

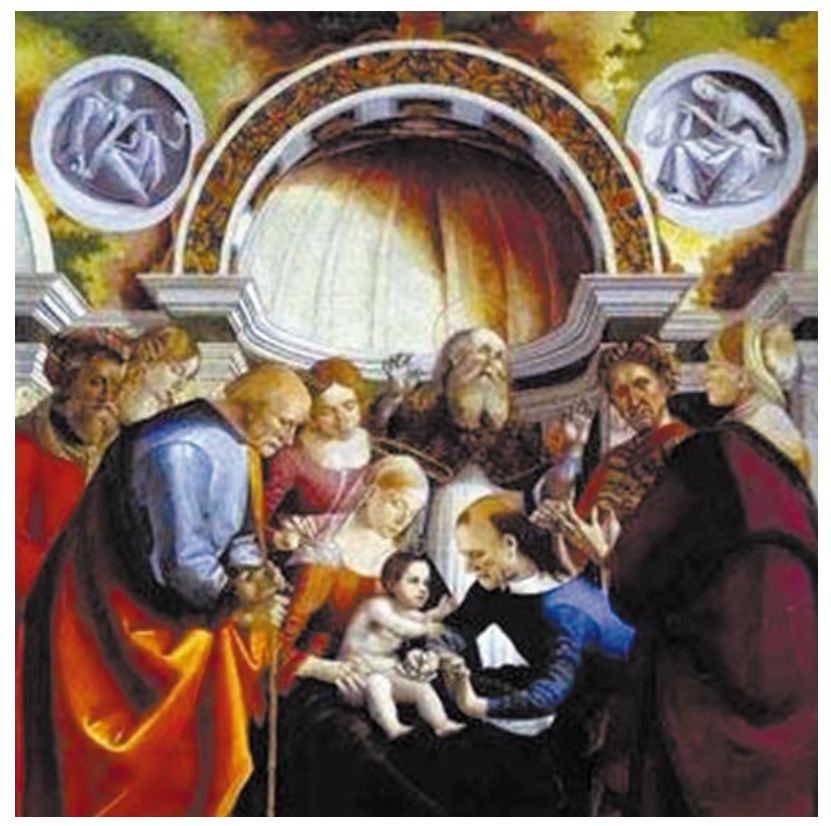

FIG URA 3: La Circuncisión de Cristo. Luca Signorelli, 1490-1495 (258,5 x 180) Engrase en madera. Renacimiento Italiano.
Habrá que esperar al renacimiento italiano para que el tema de la circuncisión a parezca de forma recurrente, y para que encontremos obras de mayor interés y que generen mayor polémica.

Parece ser éste el momento en el que hay una mayor libertad para tratar un tema tan espinoso, hasta el punto de que en la misma Capilla Sixtina encontramos, en la pared sur, junto al Juicio Final de Miguel Ángel, un interesante fresco sobre la circuncisión del segundogénito de Moisés, dentro de las Historias sobre la vida de Moisés, pintadas por los pintores más relevantes de la época, Pietro Vannuci, conocido como el Perugino, Pinturicchio, Botticcelli y Luca Signorelli, encargados desde 1481 de los frescos del muro inferior. Una inclusión imposible de imaginar en momentos de mayor turbulencia política y religiosa.

En realidad, en muchos de estos cuadros 10 que se pretende es la reafirmación del cristianismo frente al judaísmo, presentando composiciones en las que los personajes rechazan el rito, destacando en este sentido la obra de Andrea Mantenga (14311506), dedicada a la circuncisión de Cristo (Figura 2), pintada en 1460, todavía bajo el influjo de las obras de Donatello en Padua. "La circuncisión" llama la atención por el escenario suntuoso en el que se practica, un impresionante templo renacentista, con arcos de medio punto, y bajorrelieves veterotestamentarios (el sacrificio de Isaac, y Moisés mostrando las tablas de la Ley), que conectan directamente la escena con el Antiguo Testamento y con la religión judía. Lo curioso
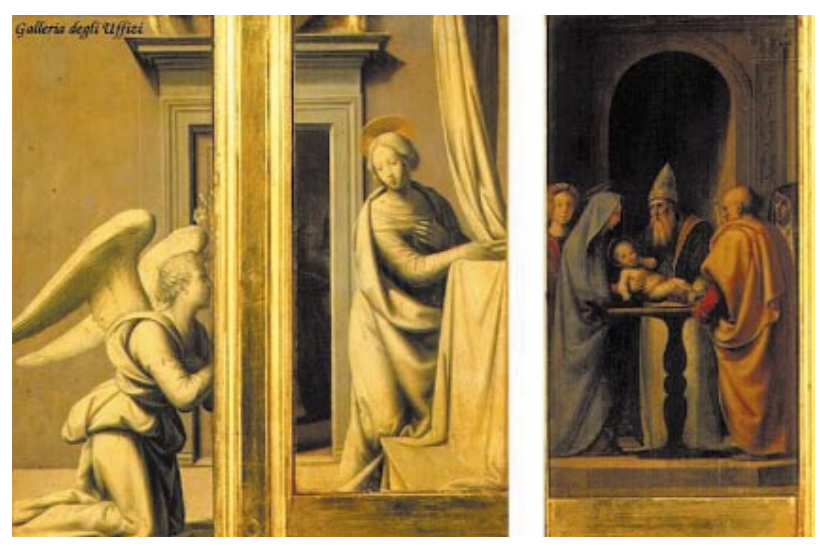

FIG URA 4: Díptico de la presentación en el Templo. Fra Bartolomeo. 1500. Renacimiento Italiano. 


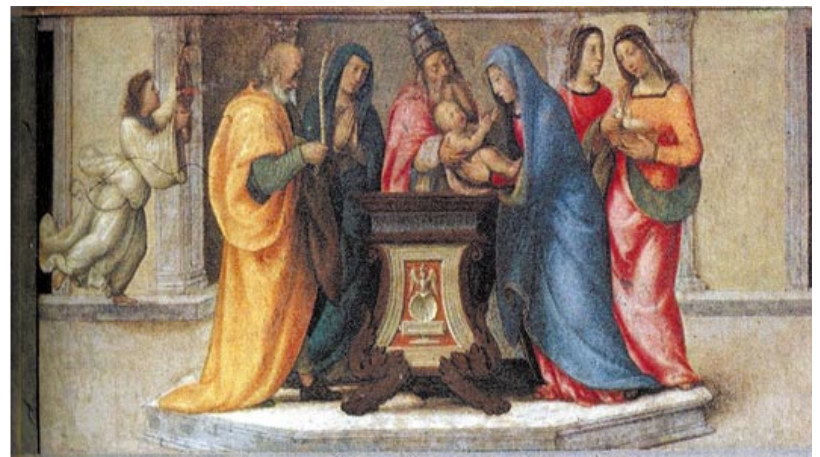

FIG URA 5: M ariotto Albertinelli. 1503. Renacimiento Italia no.

del cuadro, es que en él aparece la composición básica de la escena, con el sacerdote médico, la Virgen María y Cristo niño, pero, y esto es lo interesante, éste aparece asustado y tratando de esconderse en el seno de su madre, en clara actitud de rechazo del rito de la circuncisión, y por extensión, de la religión judía.

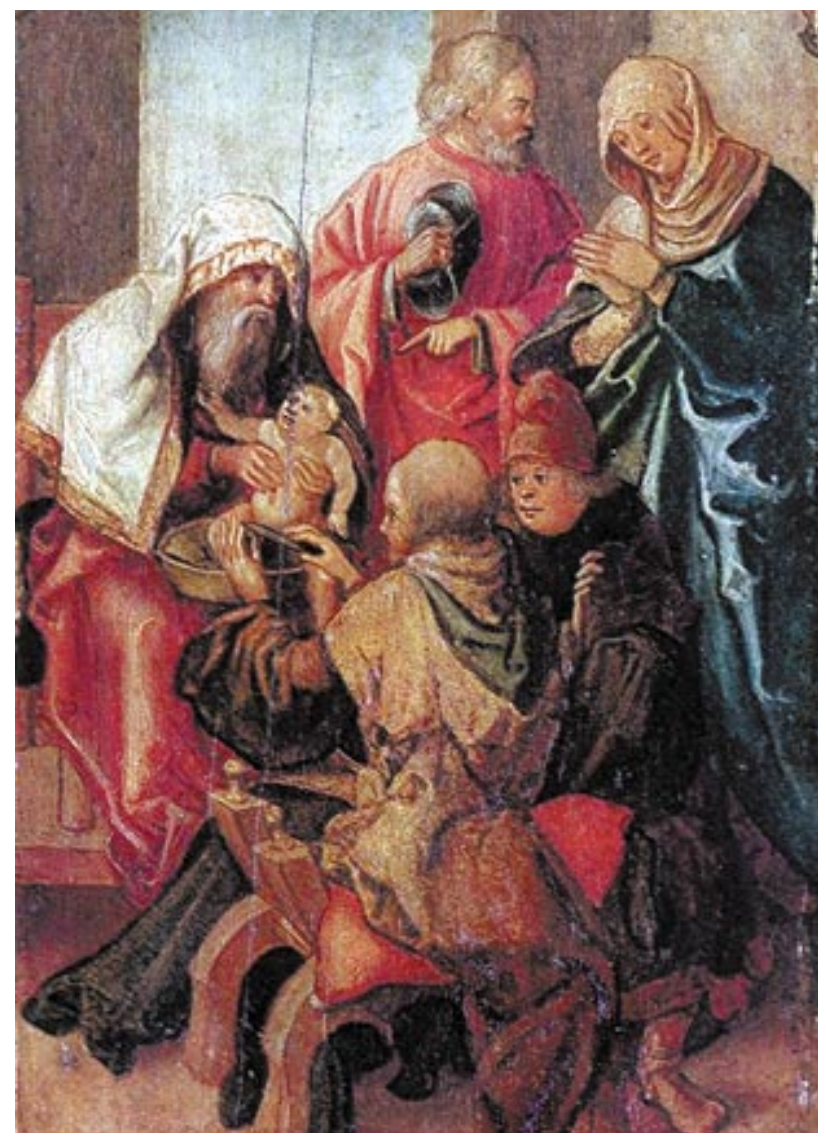

FIG URA 7: Hans Leonhard Schaufelein. Renacimiento Alemán.

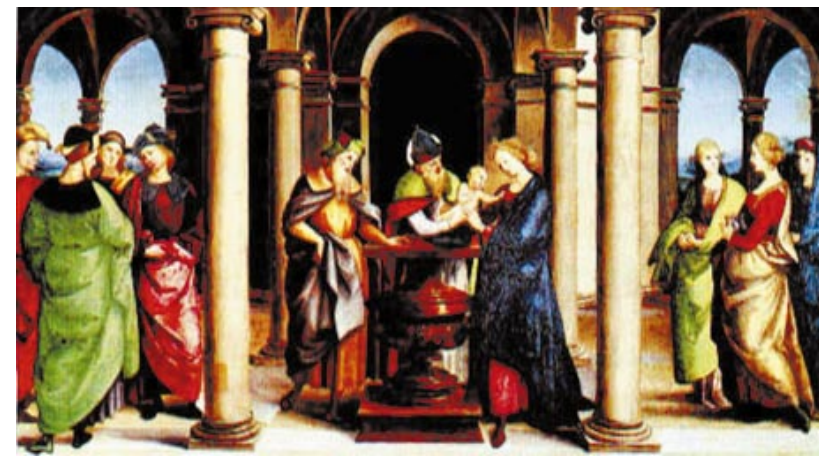

FIG URA 6: Rafael. Renacimiento Italiano. ó leo sobre tabla.

El tema sería tratado de nuevo por Luca Signorelli (1450-1523), discípulo de Piero de la Francesca, en la interesante obra "la circuncisión de Cristo" (Figura 3), pintada hacía 1490-1495, una de sus obras más importantes fuera de sus aportaciones a la Capilla Sixtina. En el centro de la obra encontramos a Cristo niño, alrededor del cual aparecen el resto de los personajes, y a los pies las Escrituras, que remiten al Antiguo Testamento, mientras que los personajes presentes muestran diferentes actitudes hacia el rito, siguiendo la línea trazada por la obra de Mantegna. (Italia, 1474-1515)

En el Cinquecento, o alto renacimiento, hay que destacar en cuanto al tema que nos ocupa, impor-

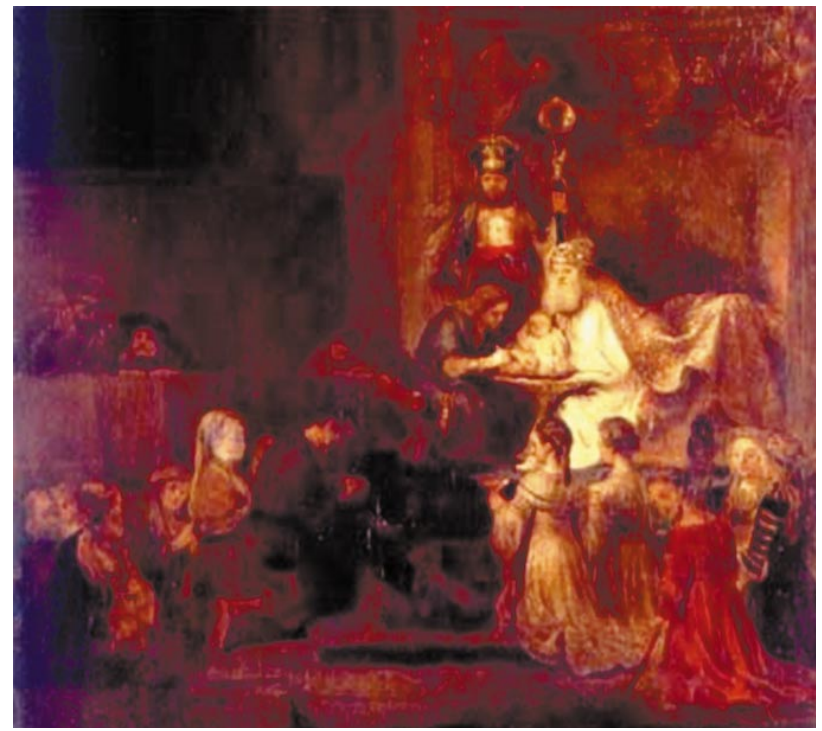

FIG URA 8: La Circuncisión. Rembrandt, 1646. Barroco centroeuropeo. 
tantes figuras como Fra Bartolomeo (1472-1517) (Figura 4), pintor imbuido de inquietudes sociales y religiosas, que le llevaron a entrar a formar parte de la orden dominicana a finales del siglo XV, dejando de lado la pintura, a la que volvería con fuerza renovada pocos años después, al quedar impresionado por la obra de Bellini y de Leonardo Da Vinci y su tratamiento del color. Su circuncisión se circunscribe a un periodo temprano dentro de su obra. Pintada hacía 1500, forma parte del Díptico de la presentación en el Templo. Y su importancia radica en su influencia sobre pintores contemporáneos, como Mariotto Albetinelli y Rafael.

Mariotto Albertinelli (1474-1515), con quien Bartolomeo llegaría a fundar un taller de pintura, retomaría el tema de la circuncisión tan sólo varios años después de él (1503) (Figura 5), y es en gran medida deudora de la obra de Bartolomeo. En cuanto a composición, y color, repite el mismo esquema, dando la sensación de estar ante dos composiciones gemelas. En ambos cuadros destacan las figuras de la Virgen, cubierta con una larga túnica azul, y el sacerdote, con mitra, que sujetan al niño que se encuentra en situación expectante. Tan sólo el escenario y algunos de los testigos del rito parecen haber cambiado.

Rafael Sanzio (1483-1520), es una de las figuras más importantes del renacimiento. Formado probablemente en el taller del Perugino donde desarrolla su estilo, lleno de emotividad y de gran delicadeza, y muy influenciado por Fra Bartolomeo. A los 25 años fue llamado por el Papa Julio II, que le encargó la decoración al fresco de sus estancias privadas en el
Vaticano, las habitaciones conocidas como "stanzen". "La circuncisión", forma parte de "la presentación en el Templo" (Figura 6), óleo sobre tabla pintado por Rafael entre 1502 y 1503, y hoy en la pinacoteca vaticana.

Fuera de las fronteras italianas, también en pleno renacimiento, destaca la obra de Hans Leonhard Schaufelein (1480-1540), pintor y grabador alemán, perteneciente a la escuela de Durero, y muy influenciado por él (Figura 7).

Posteriormente, Federico Barocci (15261612), se especializó en cuadros de temática religiosa, entre los cuales existe un importante cuadro, hoy en el M useo del Louvre, sobre la circuncisión de Cristo. El hecho de que "la circuncisión", pintado hacia 1590, sea un cuadro menos famoso que "la Virgen de las cerezas" por ejemplo, aunque estilísticamente sea similar, demuestra que la temática de la obra pudo ser considerada incómoda con posterioridad. Figura importante del manierismo, Barocci, destaca por su tratamiento poco natural del color, y del movimiento de los personajes, aunque ya deja entrever algunos de los rasgos fundamentales del barroco, como el contraste entre luces y sombras, y la búsqueda de la intimidad de la escena.

También encuadrable dentro de una etapa de transición entre las formas manieristas, y el tenebrismo naturalista del barroco español nos encontramos con el retablo mayor de la Capilla de la Universidad de Sevilla, un lienzo de grandes dimensiones, dedicado a la Circuncisión de Cristo (1606), tradiciona Imente atri-

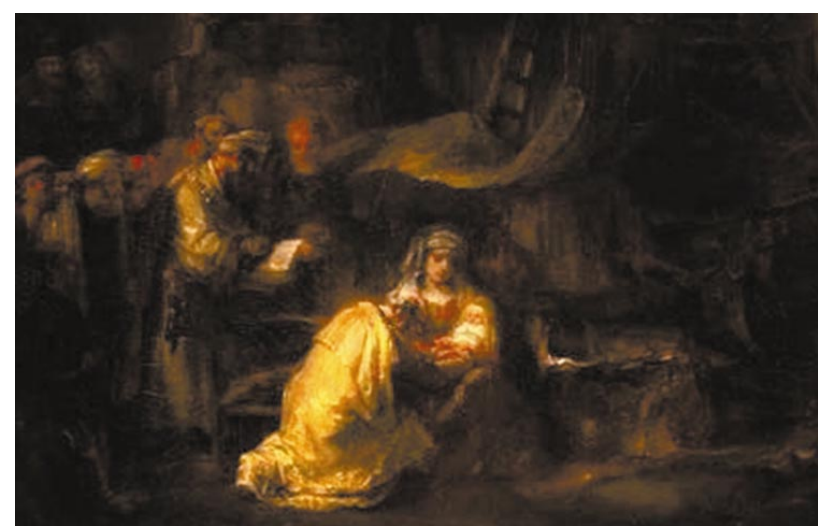

FIG URA 10: La Circuncisión. Rembrandt, 1661. Barroco centro europeo.

ó leo sobre lienzo $(56,5 \times 75 \mathrm{~cm})$. Barroco C entroeuropeo. 
buido a Juan de Roelas y que pretende más que generar algún tipo de debate o polémica, la exaltación de la Compañía de Jesús, por medio de la representación de San Ignacio de Loyola en la escena de la circuncisión (Figura 8). Juan de Roelas, capellán real desde 1614 y protegido del Conde Duque de Olivares, es una de las figuras clave de este periodo de la pintura española, destacando por su mezcla de diferentes rasgos pictóricos: a su clara influencia en cuanto al tratamiento del color de El Veronés y de Tintoretto, se une la influencia de El Greco, especialmente en cuanto al esquema compositivo (la división del cuadro religioso en dos mitades, que reflejan respectivamente el mundo terrenal y el mundo celestial).

Durante el siglo XVII, en pleno barroco, tras la division del territorio que se había denominado Países Bajos, la pintura alcanza un apogeo que le valió el

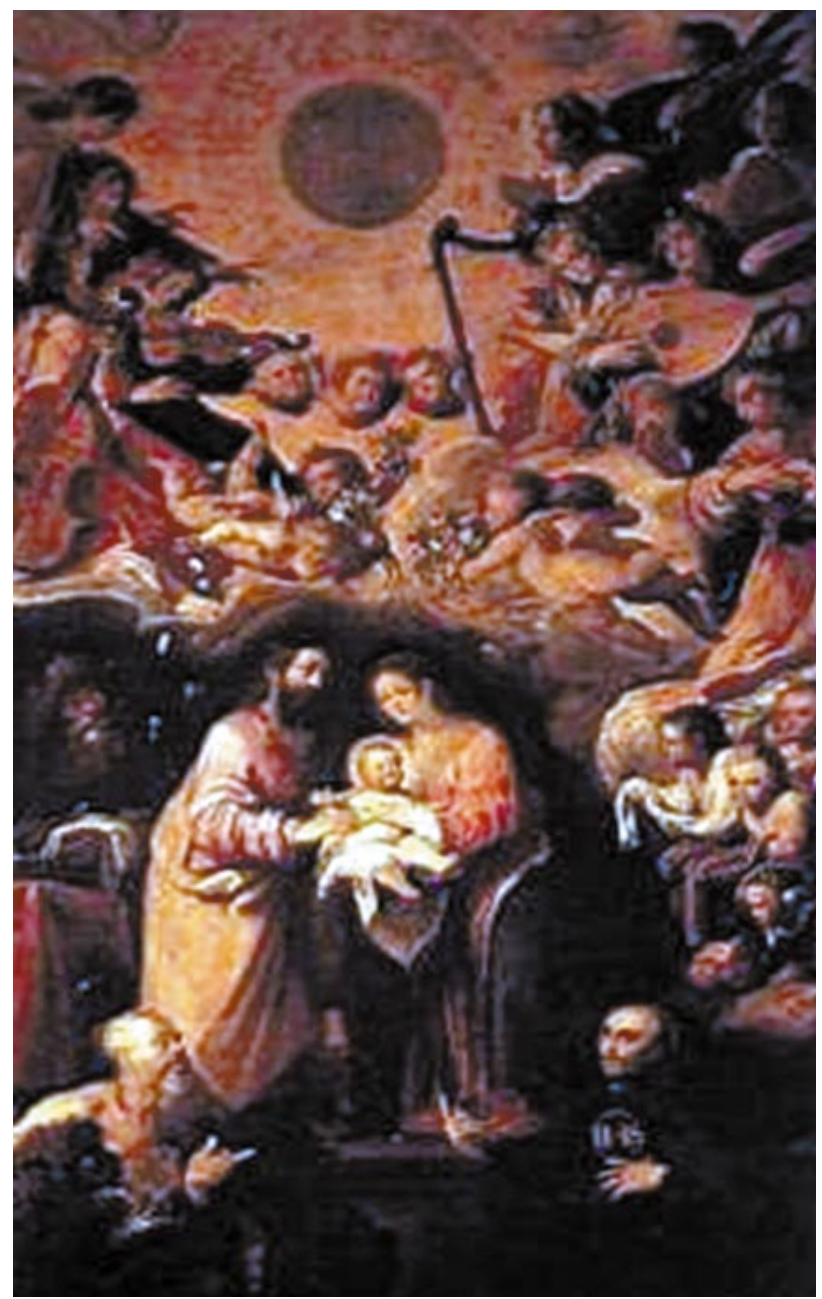

FIG URA 11: La circuncisión. Juan de Roelas. 1604. Barroco español. nombre de "Edad de 0 ro". Los nombres de Rubens, en el sur, católico, y de Rembrandt en el norte, protestante, marcan este periodo de luchas religiosas, y encarnan también dos maneras distintas de entender el arte. Precisamente de Rembrandt Harmensz Van Rijn (1606-1669), una de las figuras más importantes del barroco centroeuropeo, destaca "la circuncisión" (Figura 9), pintada en 1646 como parte de un ciclo sobre la pasión de Cristo encargado por Frederick Henrick de Orange, del que formaban parte obras como "la adoración de los pastores", "la erección de la cruz", "el descendimiento", "el entierro de Cristo", y "la ascensión", obras conservadas actualmente en la Alte Pinakotek de Munich.

El hecho de que sea la única de las obras del ciclo no conservada en nuestros días (se perdió en el siglo XVIII), hace pensar en la posibilidad de que la obra fuera destruida por la Iglesia, no sólo por tratar el polémico tema de la circuncisión, sino también por la fama de polémico y controvertido del propio autor, de vida desordenada e impía. Aunque su desaparición ha sido objeto de polémicas e incluso de leyendas negras, hay quien mantiene que fue debida en realidad a una venganza por un tema pasional. Tesis que se sostiene tal vez por el hecho de que existe otras dos obras de Rembrandt, más tardías sobre el mismo

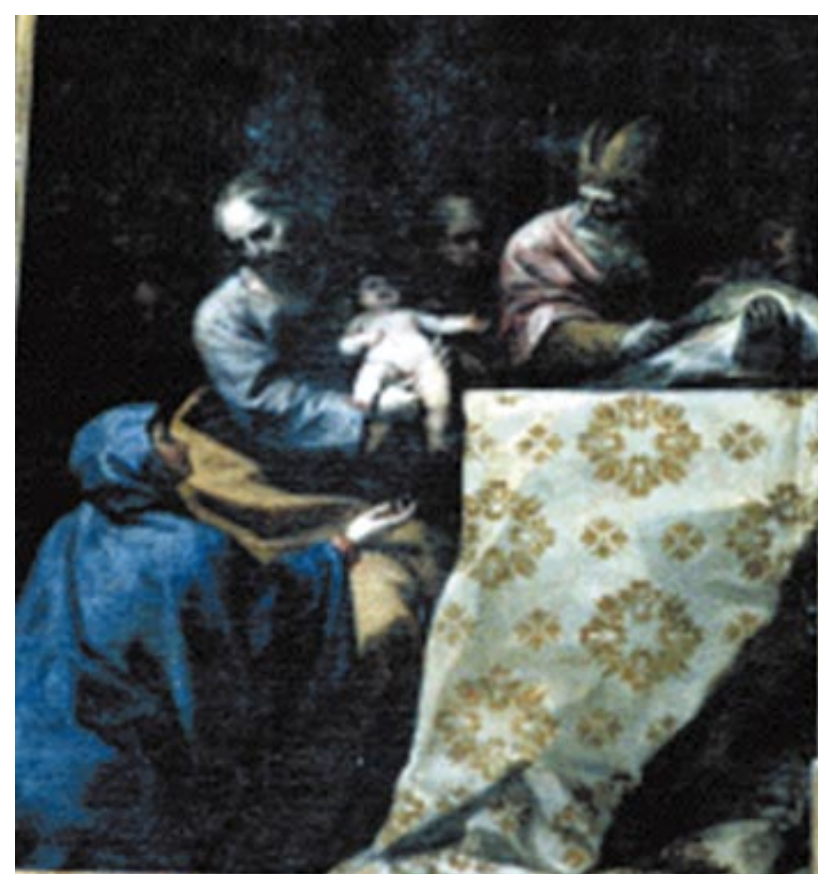

FIG URA 12: La Circuncisión. Alonso Cano, 1645. Barroco Español. 
tema, un dibujo (1654) (Figura 10), y de nuevo un óleo (1661), que todavía hoy se puede contemplar en la Nacional Gallery de Washington (Figura 11). La repetición del mismo tema a lo largo de la vida del autor nos da la oportunidad además de analizar su evolución. El hecho de que decidiera no marchase hacia el sur, como hiciera Rubens, que impregnó su obra de influencias renacentistas italianas, al servicio de la nobleza que le pagaba, Rembrandt, evolucionó hacía un interiorismo de la escena, y al resalte de los claroscuros, ambos estilos típicamente barrocos, aunque antagónicos.

También en el barroco, pero en este caso en el español, tenemos ejemplos famosos de la circuncisión, como la de Alonso Cano (1601-1667), realizada en 1645 (Figura 12). Alonso Cano, es una de las figuras españolas que mejor pueden asimilarse a la figura del genio universal renacentista, trabajando y destacando en varias artes (la pintura, la escultura y la arquitectura), como anteriormente habían hecho Miguel Ángel o Leonardo Da Vinci. Contemporáneo de Velázquez, y algo más joven que él, destacó por el tratamiento del cuerpo humano, y por la belleza y delicadeza en las representaciones femeninas. Estilísticamente Cano es barroco, y de gran influencia manierista, preocupado siempre por la corrección en el dibujo, y el trazo firme. En esta obra de transición, presenta ya Cano, alguno de sus rasgos distintivos de representación de la figura humana (delicadeza en la representación del cuerpo humano) y de sus vestiduras, aunque no es una de sus obras más importantes 0 afamadas.

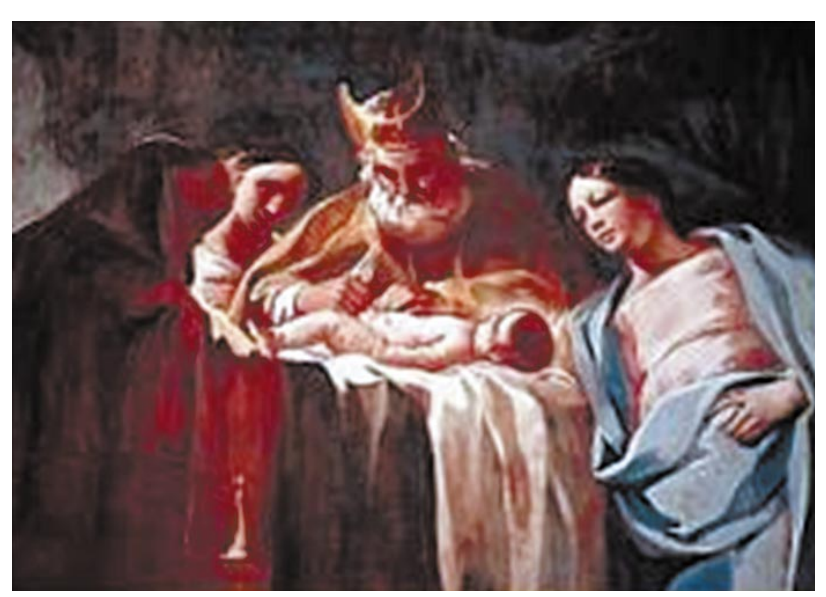

FIG URA 13: La Circuncisión, Francisco de G oya y Lucientes (305 x 1.025). Ó leo sobre muro). Iglesia de la Cartuja del Aula Dei.
Francisco de Goya y Lucientes (1746-1828), pintor y grabador español formado en el barroco, bebiendo de la influencia de Velázquez y Rembrandt, trató el polémico tema (la Circuncisión. $305 \times 1.025$. Ó leo sobre muro), como parte de un ciclo de once elementos realizados al óleo dedicado a la Virgen María y a la infancia de Cristo, pintados para decorar la Iglesia de la Cartuja del Aula Dei (hacia 1774) (Figura 13), que se enmarcan estilísticamente, dentro de una etapa temprana de Goya (tan sólo tenía entonces 28 años). El esquema de "la circuncisión" de Goya nos traslada directamente al grupo central, con el sacerdote médico, con Cristo niño sobre sus rodillas y la Virgen María, cuyo rostro genera ternura y paz, girando la cabeza hacia su hijo, en una hermosa composición, acompañados de figuras secundarias, siguiendo el esquema clásico, y sin evolución desde el gótico, pero profundizando a través de pinceladas pequeñas en los contrastes de luz y color.

Con el paso de los años, el tema ha perdido importancia dentro de la pintura religiosa, y definitivamente aparece en un segundo plano. En el siglo XX, obras como "La Circuncisión" (1946) de Jackson Pollock (1912-1956), se circunscribe dentro de su período surrealista, todavía muy dependiente de Picasso, aunque ya dando paso al estilo personal de Pollock (dripping o goteo). La obra sin embargo, no pretende polémica religiosa de ningún tipo, sino que viene a reflejar más el sentimiento de dolor y la violencia del momento.

\section{BIBUOGRAFÍA}

1. WALTER INGO, F.: "Los maestros de la pintura occidental". Editorial Taschen. Madrid. 2000.

2. GANNE, E.; MÉLY, J.; PASSELIGUE, M. y cols.: "Le grand dictionnaire de la peinture. Des origins a nos jours”. EDDL. Amstel veen. Países Bajos. 1992.

3. RAMIREZ, J. A.: "Historia del Arte en la Edad Media". Alianza Editorial Pags. 310-318. Madrid. 2004.

4. STUKENBROCK, C.; TÖPPER, B.: "1.000 obras maestras de la pintura europea. Del siglo XIII al XIX". Kónemann. Páginas 110-114; 131; 273; 275-276. Barcelona. 2000.

5. COULINO, I. P.: "Diccionario de las Religiones". Editorial Paidos. Barcelona. 2004.

6. DION, C.: "Historia Augusta". Had. 14, 2, sobre la circuncisión; Historia romana 69. 12-15, sobre Aelia Capitolina. 